\title{
Bursitis gotosa: hallazgos por resonancia magnética
}

\author{
Gouty bursitis: magnetic resonance imaging findings \\ José Alejandro Castillo García, * Héctor Mauricio Bazaldúa Cheda, * \\ René Machorro Atempa, * María de Guadalupe Gómez Pérez ${ }^{\ddagger}$
}

Citar como: Castillo GJA, Bazaldúa CHM, Machorro AR, Gómez PMG. Bursitis gotosa: hallazgos por resonancia magnética. Acta Med Grupo Angeles. 2021; 19 (2): 289-291. https://dx.doi.org/10.35366/100458

Masculino de 40 años de edad que refiere aparición de zona de enrojecimiento y pequeño abultamiento a nivel del codo izquierdo de tres semanas de evolución, inicialmente adjudicada a piquete de insecto. Acude a médico particular que le administra tratamiento antibiótico sin mejoría, por lo que acude a una segunda evaluación médica donde a la exploración física se evidencia un notable aumento de volumen en región olecraneana, de consistencia blanda con eritema, razón por la que su médico decide investigar a fondo y solicita estudios de laboratorio, los cuales revelaron una elevación de los niveles séricos de ácido úrico y se diagnosticó con gota, por tal motivo se solicita resonancia magnética de codo izquierdo. En el estudio de resonancia magnética simple se identifica una imagen sacular a nivel del olecranon, bien delimitada, heterogénea en su interior, de comportamiento isointenso heterogéneo en el $\mathrm{T} 1$, hiperintenso heterogéneo en el T2 e hiperintenso heterogéneo en el T2 con saturación grasa. Dicha imagen midió $39.8 \times 14.8$ $\mathrm{mm}$ en el plano axial, $18 \times 46.5 \mathrm{~mm}$ en el plano sagital y $40.21 \times 46.07 \mathrm{~mm}$ en el plano coronal (Figuras 1 a 3), con una pared que midió $2.42 \mathrm{~mm}$ de grosor (Figura 2); localizada a nivel de las bursas del olécranon en específico a nivel de la bursa olecraneana superficial.
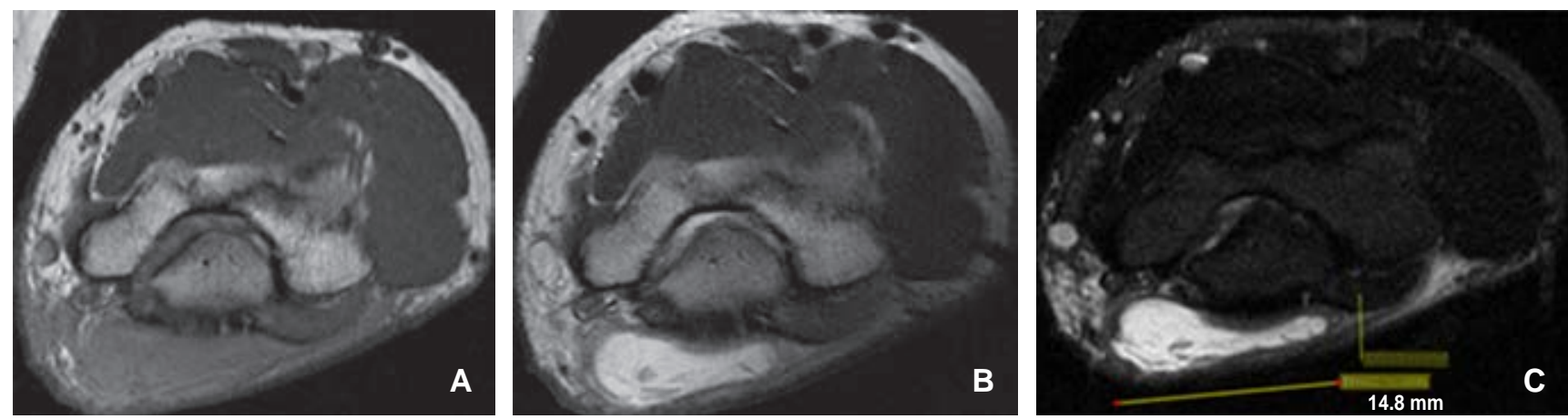

Figura 1: Imágenes adquiridas en plano sagital en secuencias ponderadas en T1 (A), T2 (B) y T2 con supresión grasa (C) que muestran un aumento de volumen a nivel de la bursa olecraneana superficial de comportamiento descrito. Es notable la presencia de imágenes hipointensas dentro de la bursa olecraneana superficial (B y C) así como las mediciones en el plano axial (C) de $39.81 \times 14.8 \mathrm{~mm}$.

\section{WVWW.medigraphic.org. mx}

* Médico Residente.

₹ Profesora Titular.

Curso de Alta Especialidad en Resonancia Magnética del Sistema Músculo Esquelético, Hospital Ángeles Pedregal. Ciudad de México.
Correspondencia:

José Alejandro Castillo García

Correo electrónico: jacastillo072@gmail.com

Aceptado: 29-01-2020.

www.medigraphic.com/actamedica 
Figura 2:

Resonancia magnética en adquisición sagital ponderada en T2 (A) y T2 con supresión grasa (B) donde se demuestra la heterogeneidad del interior de la bursa olecraneana superficial en relación con cristales de urato así como el grosor de la pared de la bursa (A) (2.42 mm) y las mediciones de la bursa al momento de la adquisición de imágenes en un plano sagital (18 $\times 46.49 \mathrm{~mm}$ ) (B).
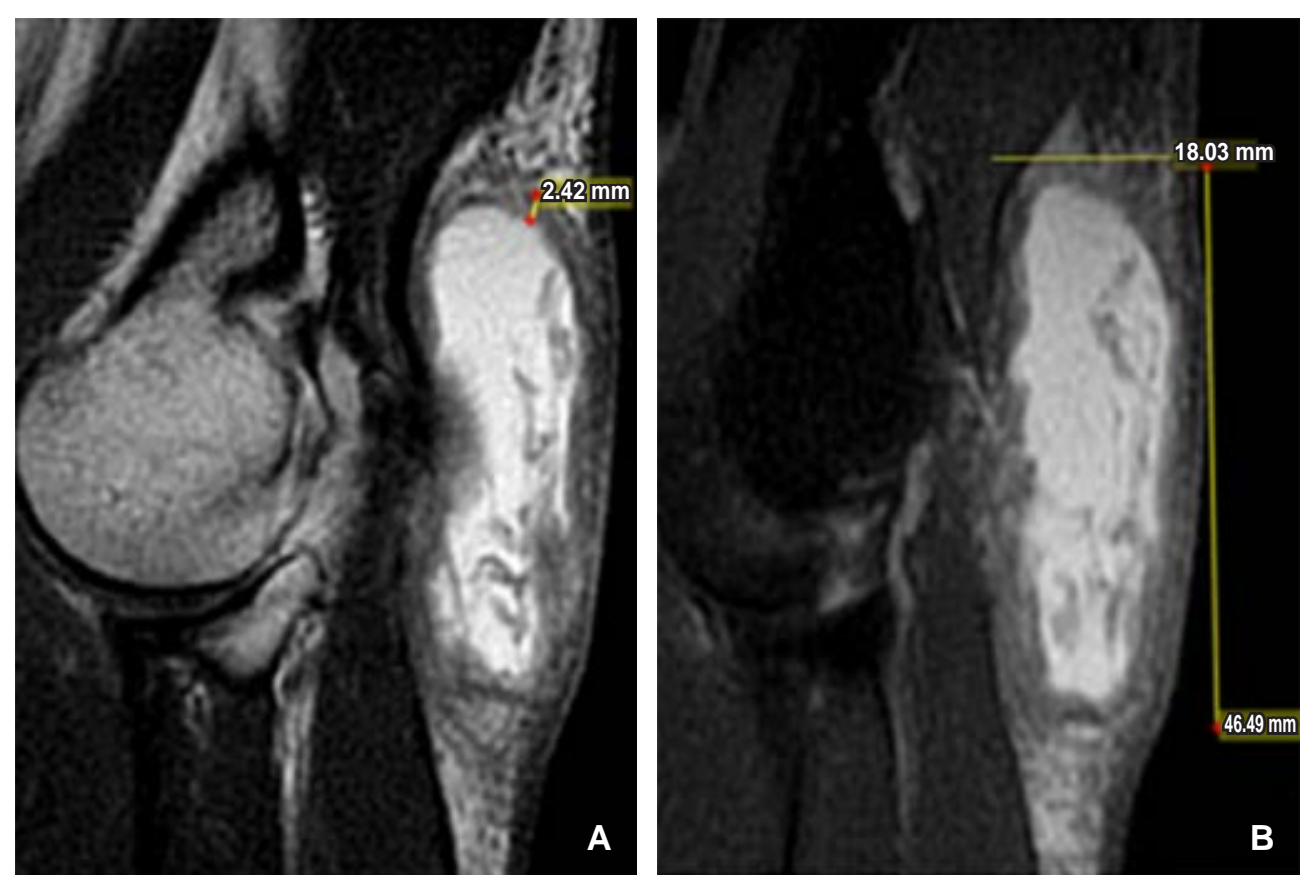
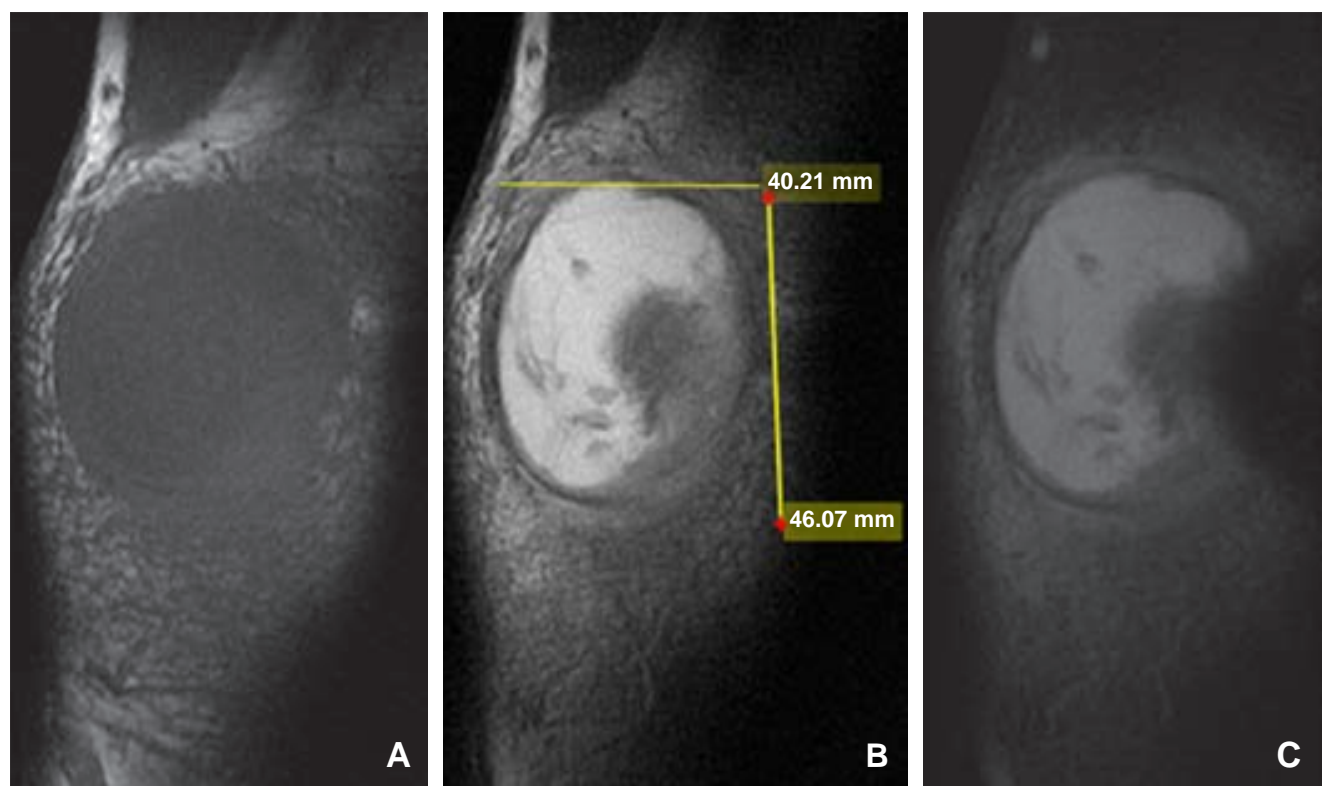

Figura 3:

Adquisición de imágenes en plano coronal en secuencias T1 (A), T2 (B) y T2 con supresión grasa (C) que demuestran las dimensiones de la bursa olecraneana en el plano coronal (B) y la heterogeneidad del contenido líquido de la bursa (B y C).

Las bursas se definen como espacios virtuales que pueden ser ocupados por líquido, delimitados por una membrana sinovial con una capa interna capilar de líquido sinovial. Provee un sistema de amortiguación entre huesos y tendones o músculos alrededor de una articulación, lo que permite reducir la fricción entre estructuras. ${ }^{1}$ Dentro de las diferentes etiologías identificamos las de sobreuso, traumatismo, infeccioso e inflamatorio tales como artritis reumatoide o gota. ${ }^{2}$
En el contexto de la enfermedad gotosa es posible observar manifestaciones articulares así como extraarticulares; ${ }^{2}$ tal es nuestro caso con afectación bursal. Las características por resonancia magnética son aumento en la cantidad de líquido sinovial articular; pueden observarse lesiones óseas en sacabocado y ocasionalmente podemos documentar bursitis olecraneanas o prepatelares. Es de importancia mencionar que los tofos se realzan tras la aplicación de gadolinio. ${ }^{3}$ 


\section{REFERENCIAS}

1. Jones J. Bursa. Radiology reference article. Radiopaedia.org [Internet]. Radiopaedia.org. 2019 [cited 6 November 2019]. Available from: https://radiopaedia.org/articles/bursa
2. Yu JS, Chung C, Recht M, Dailiana T, Jurdi R. MR imaging of tophaceous gout. AJR Am J Roentgenol. 1997; 168 (2): 523-527.

3. Meena GL, Razak K, Gupta S. Validation of MRI in the assessment of tophaceous gout: an imaging panegyric. Rheumatol Arthritic Dis. 2017; 2 (4): 1-3. 